\title{
RESEARCH
}

Open Access

\section{Immunomodulatory effect of mesenchymal stem cells in chemical-induced liver injury: a high-dimensional analysis}

Jingqi Liu', Bing Feng ${ }^{1}$, Yanping Xu' ${ }^{1}$, Jiaqi Zhu ${ }^{1}$, Xudong Feng ${ }^{1}$, Wenyi Chen ${ }^{1}$, Xinyu Sheng ${ }^{1}$, Xiaowei Shi ${ }^{3}$, Qiaoling Pan ${ }^{1,2}$, Jiong $\mathrm{Yu}^{1,2}$, Xun Zeng ${ }^{1,2}$, Hongcui Cao ${ }^{1,2,4^{*}}$ (D) and Lanjuan $\mathrm{Li}^{1,2}$

\begin{abstract}
Background: The efficacy of mesenchymal stem cell (MSC)-based therapy for acute liver injury (ALI) involves coordination with the hepatic immune system, a complex and coordinated network of immune-cell interactions. However, studies of the immunomodulatory effects of MSCs have focused on a limited number of cell subsets rather than a systematic assessment.
\end{abstract}

Methods: Carbon tetrachloride $\left(\mathrm{CCl}_{4}\right)$ was used to induce ALI in mice. To determine the efficacy of MSCS, ALI mice were injected with MSCs via the tail vein, and histopathological changes, survival rate, and the serum levels of liver enzymes were determined. To assess the immune response induced by MSCs, a mass cytometry panel of 43 metal isotope-tagged antibodies was used to characterize the hepatic immune compartment at days 1, 2, 3, and 7 after administration of MSCS or PBS.

Results: MSC treatment significantly alleviated $\mathrm{CCl}_{4}$-induced $\mathrm{ALI}$ and improved the survival rate. MSC treatment also modulated the hepatic immune system in terms of the distribution of immune-cell subsets and the phenotype of single cells. During the injured phase, MSCs inhibited a systemic response by reducing the numbers of $\operatorname{Ly} 6 \mathrm{C}^{\text {low }} \mathrm{CD}^{+}$ $\mathrm{T}_{\mathrm{RM}}$ cells, conventional NK cells, and $\mathrm{gMM}^{+} \mathrm{IgD} \mathrm{D}^{+} \mathrm{B}$ cells; suppressing the activation of $\mathrm{Ly}_{6} \mathrm{C}^{\text {hi }} \mathrm{CD}^{+} \mathrm{T}_{\mathrm{RM}}$ cells; downregulating $\mathrm{MHC} I I$ and $\operatorname{lgM}$ expression in $\operatorname{lgM}^{+} \lg \mathrm{D}^{+} \mathrm{B}$ cells; and increasing the number of immunosuppressive monocyte-derived macrophages. During the recovery phase, MSCs promoted the retention of $\mathrm{Ly}_{6 \mathrm{C}} \mathrm{C}^{\mathrm{low}} \mathrm{CD} 8^{+} \mathrm{T}_{\mathrm{RM}}$ cells and maintained the immunosuppressive activity of monocyte-derived macrophages. The response to MSC treatment differed between the injured and recovery phases, emphasizing the benefit of dynamic assessment of the immunomodulatory effects of MSCs.

Conclusions: We determined the immunomodulatory effects of MSC treatment on the subtype distribution and phenotypes of hepatic immune cells.

Keywords: Mass cytometry, Immune atlas, Mesenchymal stem cells, Immunomodulation, Adaptive immune cell, Innate immune cell

\footnotetext{
* Correspondence: hccao@zju.edu.cn

'State Key Laboratory for the Diagnosis and Treatment of Infectious Diseases,

The First Affiliated Hospital, College of Medicine, Zhejiang University, 79

Qingchun Rd, Hangzhou City 310003, China

${ }^{2}$ National Clinical Research Center for Infectious Diseases, The First Affiliated

Hospital, College of Medicine, Zhejiang University, 79 Qingchun Rd,

Hangzhou City 310003, China

Full list of author information is available at the end of the article
}

(c) The Author(s). 2019 Open Access This article is distributed under the terms of the Creative Commons Attribution 4.0 International License (http://creativecommons.org/licenses/by/4.0/), which permits unrestricted use, distribution, and reproduction in any medium, provided you give appropriate credit to the original author(s) and the source, provide a link to the Creative Commons license, and indicate if changes were made. The Creative Commons Public Domain Dedication waiver (http://creativecommons.org/publicdomain/zero/1.0/) applies to the data made available in this article, unless otherwise stated. 


\section{Background}

Acute liver injury (ALI) induced by chemicals or viruses can progress rapidly to acute liver failure, for which liver transplantation is indicated [1]. However, because organ shortages and transplantation complications limit the applicability of this therapy, novel therapies are required. ALI involves the infiltration of immune cells, such as T cells, B cells, and natural killer (NK) cells $[2,3]$. Immunosuppressive treatments and decreased inflammation reportedly promote repair after ALI [2]. Thus, transplantation of mesenchymal stem cells (MSCs) shows promise for ALI because of its immunomodulatory and immunosuppressive effects.

MSCs are multipotent stromal cells that can be isolated from various tissues and can differentiate into several lineages of cells, including osteoblasts, adipocytes, and chondrocytes [4]. Previous animal and clinical studies have shown that transplantation of MSCs ameliorates liver injury by inhibiting the activation and function of various immune cells, such as suppressing $\mathrm{T}$ cell proliferation, downregulating the proliferation and cytotoxicity of NK cells, and suppressing the maturation of monocytes into dendritic cells (DCs) [4-6]. Due to the limitations of flow cytometry, studies of the immunomodulatory effect of MSCs have focused on individual cell subsets. However, the immune system is a complex and mobile network of various cells and molecules, and therefore, systematic analyses of the interaction between the immune system and MSCs in ALI are needed.

High-dimensional mass cytometry combines flow cytometry and mass spectrometry. This technology uses stable heavy-metal isotopes in place of fluorophores and thus is not limited by spectral overlap of fluorophores and enables the simultaneous measurement of $>40$ parameters at the single-cell level [7-10]. Therefore, mass cytometry enables systematic analyses of immune cell dynamics and system-wide assessment of the efficacy of MSCs against ALI.

In this study, we used high-dimensional mass cytometry to identify differences in the liver immune-cell landscape and dynamics in mice with carbon tetrachloride $\left(\mathrm{CCl}_{4}\right)$-induced ALI treated with MSCs or not. We profiled the immunomodulatory effects of MSCs on the hepatic immune system including the distribution and phenotypes of immune-cell subsets at single-cell resolution. Our data expand knowledge of the immunomodulatory effects of MSCs on the hepatic immune system, which will facilitate the development of MSC-based treatments for ALI.

\section{Methods}

\section{MSC treatment of mice with ALI}

To determine the efficacy of MSCs against ALI, MSCs at passages 3 to 5 isolated from compact bone of C57BL/6 mice were characterized by inducing osteogenic and adipogenic differentiation and analyzing surface marker expression by flow cytometry (Additional file 1: Figure S1). Six- to eight-week-old male C57BL/6J mice were intraperitoneally administered $3 \mathrm{~mL} / \mathrm{kg}$ of $\mathrm{CCl}_{4}$ (Sigma-Aldrich Co. LLC, St. Louis, MO, USA) diluted in olive oil (v/v, 50\%, Sigma-Aldrich) to induce ALI. Control mice received olive oil alone. Six hours after $\mathrm{CCl}_{4}$ administration, the mice with ALI were divided into the MSC group (injected into the tail vein with $5 \times 10^{5}$ MSCs in $0.1 \mathrm{~mL}$ of PBS containing $2 \%$ mice serum) and placebo (PBS) group (injected into the tail vein with an equal volume of PBS containing $2 \%$ mice serum). Control mice were injected with an equal volume of PBS containing 2\% mice serum (control group). The mice were euthanized on days $1,2,3$, and 7 after MSC or PBS administration, and liver tissue and serum were collected for histological and biochemical analyses. Mortality was recorded every $24 \mathrm{~h}$ until day 7 post-transplantation (Fig. 1a).

\section{Antibody labeling}

A mass cytometry panel of 43 metal isotope-tagged antibodies (Additional file 1: Table S1) was used to evaluate the adaptive and innate immune cell populations in the mouse liver. The antibodies were conjugated to the indicated metal tags using a MaxPAR X8 Antibody Conjugation Kit (Fluidigm, San Francisco, USA) according to the manufacturer's protocol. The conjugated antibodies were diluted to $200 \mathrm{mg} / \mathrm{mL}$ in Candor Antibody Stabilizer (Sigma) and titrated to the optimal concentrations.

\section{High-dimensional analysis}

Single-liver-cell suspensions were washed once with 1 $\mathrm{mL}$ of fluorescence-activated cell sorting (FACS) buffer (PBS with $0.5 \% \mathrm{BSA}$ and $0.02 \% \mathrm{NaN}_{3}$ ) and incubated in $0.25 \mu \mathrm{M}$ cisplatin (Fluidigm) for $5 \mathrm{~min}$ on ice to enable discrimination of dead cells. The cells were washed with FACS buffer, after which $20 \mathrm{mg} / \mathrm{mL}$ mouse/hamster/rat total IgG (Equitech-Bio, Inc., Cotton Gin Lane, Kerrville, USA) was added to block Fc receptors, and then, the cells were incubated on ice for $20 \mathrm{~min}$. Next, the cells were reacted with an anti-CD49a-APC primary antibody $(100 \mu \mathrm{L})$ for $30 \mathrm{~min}$ on ice. The single-cell suspensions were reacted with $100 \mu \mathrm{L}$ of a metal-isotope-conjugated antibody cocktail (Additional file 1: Table S1) for $30 \mathrm{~min}$ on ice. The cells were washed twice and incubated in $0.03 \mu \mathrm{M}$ Ir nucleic-acid intercalator (Fluidigm) in Fix and Perm Buffer (Fluidigm Sciences) at $4{ }^{\circ} \mathrm{C}$ overnight. The cells were washed with Perm Buffer (eBioscience Inc., San Diego, CA, USA) and stained with $100 \mu \mathrm{L}$ of a metal isotope-conjugated intracellular antibody cocktail (Additional file 1: Table S1) in Perm buffer for $30 \mathrm{~min}$ on ice. 


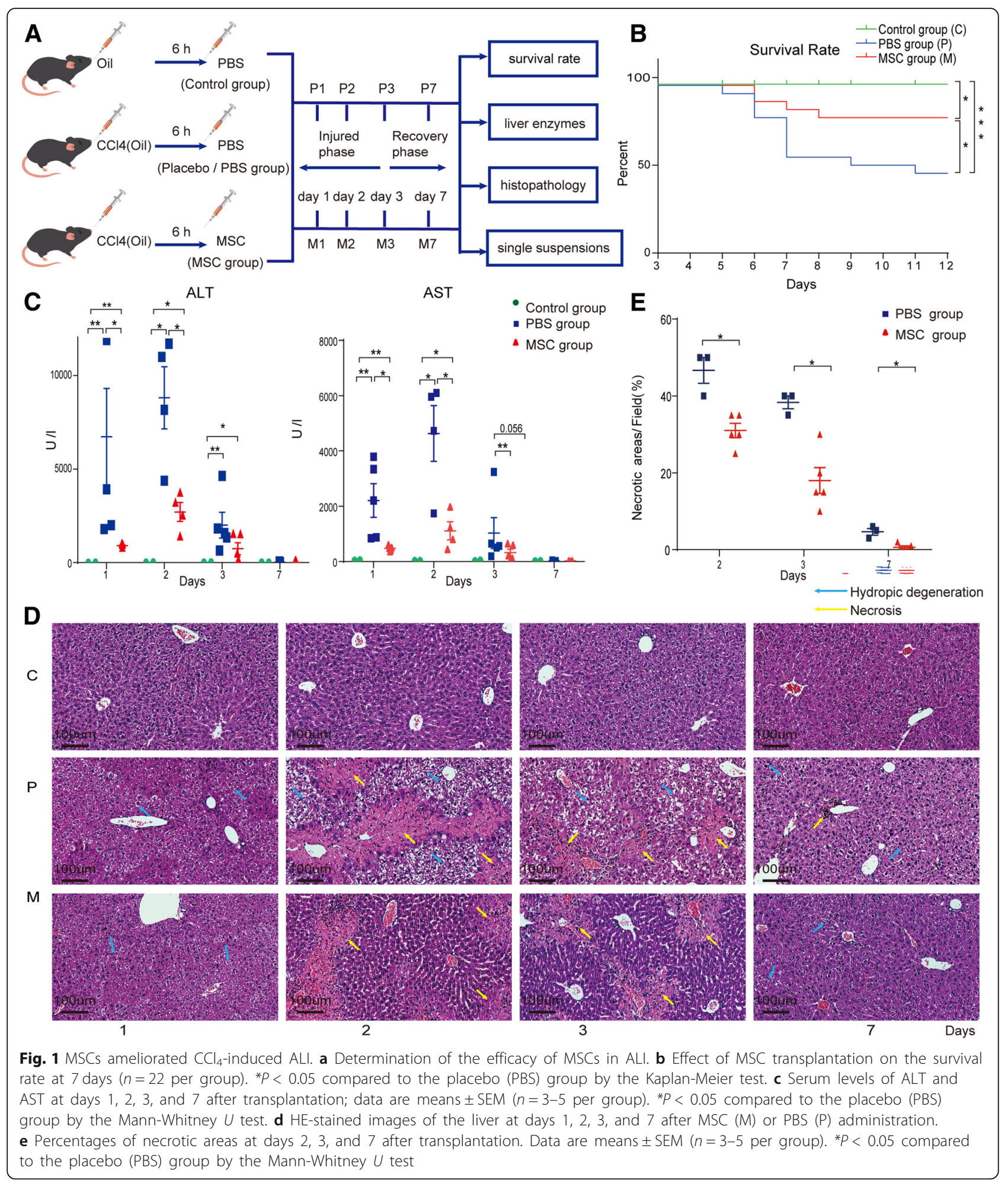

The cells were counted, resuspended at $0.6 \times 10^{6} / \mathrm{mL}$ in distilled water containing 20\% EQ. 4 beads (Fluidigm), and filtered through capFACS tubes (Corning). Mass cytometry data were acquired using a Helios system (Fluidigm Sciences) at $\leq 500$ events per second.
Raw mass cytometry data in .fcs files were manually gated as live, singlet, and valid immune cells (Additional file 1: Figure S2). The data were subjected to the metal isotope beads normalization method. The gated cell populations were clustered using the X-shift algorithm in 
MATLAB. The signal intensities of the markers were transformed using Arcsinh with a cofactor of 5, and the transformed signal intensities were normalized as follows: the top $1 \%$ was excluded, and the maximum signal intensity of each marker was defined as the 99th percentile. All of the data were divided by this value, yielding single intensities for each channel of 0 to 1 . Normalized marker expression levels were visualized as heatmaps. The percentage of each cluster was calculated as the percentage of live and singlet $\mathrm{CD} 45^{+}$cells. Clusters with proportions of less than $0.1 \%$ were ignored. To visualize the high-dimensional data in two dimensions, data from 10,000 randomly selected cells from each sample were processed using the nonlinear dimensionality reduction algorithm t-Distribution Stochastic Neighbor Embedding (t-SNE) [11-13]. viSNE maps were generated using MATLAB (MATLAB Release 2015b macOS 64-bit version, MathWorks, Inc., Natick, MA, USA).

\section{Statistical analyses}

The data are presented as means \pm standard error of the mean (SEM). The significance of differences was assessed by the paired $t$ test, the Kaplan-Meier test, and Pearson correlation coefficients using the Statistical Package for the Social Sciences (SPSS) (ver. 19.0; IBM Corp., NY, USA). The heatmap in Fig. 2 was generated in MATLAB; other heatmaps and three-dimensional bar plots were generated in Origin (ver. 2017SR2; OriginLab $^{\oplus}$, Northampton, MA, USA).

The procedures for animal experiments, isolation and culture of mouse MSCs, osteogenic and adipogenic differentiation assay, flow cytometry, biochemical tests, and preparation of total liver single-cell suspensions are described in the Additional file 1.

\section{Results}

\section{MSCs ameliorate $\mathrm{CCl}_{4}$-induced ALI}

To determine the efficacy of MSCs in ALI, we recorded the survival rate (Fig. 1a). At 7 days after MSC administration, the survival rate of the MSC group was significantly greater $(p<0.05)$ than that of the placebo group $(82 \%$ vs. $54.5 \%)$ (Fig. 1b). Next, the serum levels of liver enzymes were determined (Fig. 1c and Additional file 1: Figure S3A). The alanine aminotransferase (ALT) and aspartate aminotransferase (AST) levels peaked at 2 days and then gradually recovered to an almost normal level at 7 days after MSC or placebo administration. The peak levels were significantly lower in the MSC group than in the placebo group $(p<0.01)$ (Fig. 1c). After PBS administration, sequential histopathological changes typical of ALI were observed microscopically, including diffuse hepatocyte hydropic degeneration on day 1 and diffuse hepatic necrosis on day 2; at day 7, only slight edema and individual necrotic cells were observed. In contrast, hepatic necrosis in the MSC group was markedly ameliorated on days 1,2 , and 3 after MSC administration compared to the placebo group and had recovered to almost normal at day 7 (Fig. 1d). The necrotic areas in the livers of MSC-treated mice showed remarkable recovery on days 2, 3 , and 7 compared to the placebo group (Fig. 1e). Therefore, MSC administration significantly alleviated $\mathrm{CCl}_{4}$-induced ALI. Additionally, to exclude off-target effects, $\mathrm{GFP}^{+}$ MSCs were detected in suspensions of liver parenchymal cells from ALI mice (Additional file 1: Figure S3B-S3E), and no $\mathrm{GFP}^{+}$MSC engraftment was detected by PCR in the lung, spleen, blood, lymph node, heart, or kidney at 1 , 3,5 , or 7 days after MSC administration (not shown).

\section{High-dimensional mass cytometry analysis of the mouse liver immune system}

To validate the mass cytometry results, we identified the major cell subsets ( $\mathrm{T}$ cells, B cells, NK cells, and myeloid cells) by mass cytometry and fluorescence flow cytometry (Additional file 1: Figure S4A and S4B). The relative frequencies of each subset by mass cytometry were similar to those obtained by flow cytometry (Additional file 1: Figure $\mathrm{S} 4 \mathrm{C}$ ), confirming the reliability of the mass cytometry data. To comprehensively analyze the mouse liver immune landscape and the interaction between hepatic immune-cell subsets and MSCs, we characterized the liver immune compartment at days 1, 2, 3, and 7 after administration of MSCs or PBS (Fig. 2A).

\section{Identification of major immune-cell lineages in ALI}

To generate a comprehensive view of the liver immune system, mass cytometry data were processed using the nonlinear dimensionality reduction algorithm t-SNE [11-13]. We analyzed the distribution of major immune cell lineages of mice livers in three groups (Fig. 2B-F, Additional file 1: Figure S5). A significantly larger number of immune cells were present in the livers of mice with ALI compared to control mice. The number of immune cells peaked at day 2 and gradually decreased up to day 7 (Fig. 2C). This pattern is consistent with the marked upregulation of Ki-67 expression on $\mathrm{CD} 45^{+}$liver immune cells after ALI, which peaked at day 2 and gradually decreased up to day 7 (Fig. 2D). These results, together with the serum levels of liver enzymes and histopathological changes, indicate that immune activation and liver injury are discernable by day 2 after ALI (the injured phase) and recover by day 7 (the recovery phase).

The composition and dynamics of the liver immune-cell populations differed among the three groups. In general, the adaptive lymphocyte subsets, $B$ and $T$ cells, were most abundant in the liver immune cell compartment of the control mice (30.1\% and $21.3 \%$, respectively); the mean proportion of mononuclear phagocytes was $20.3 \%$. In mice with ALI, the proportion of mononuclear phagocytes 


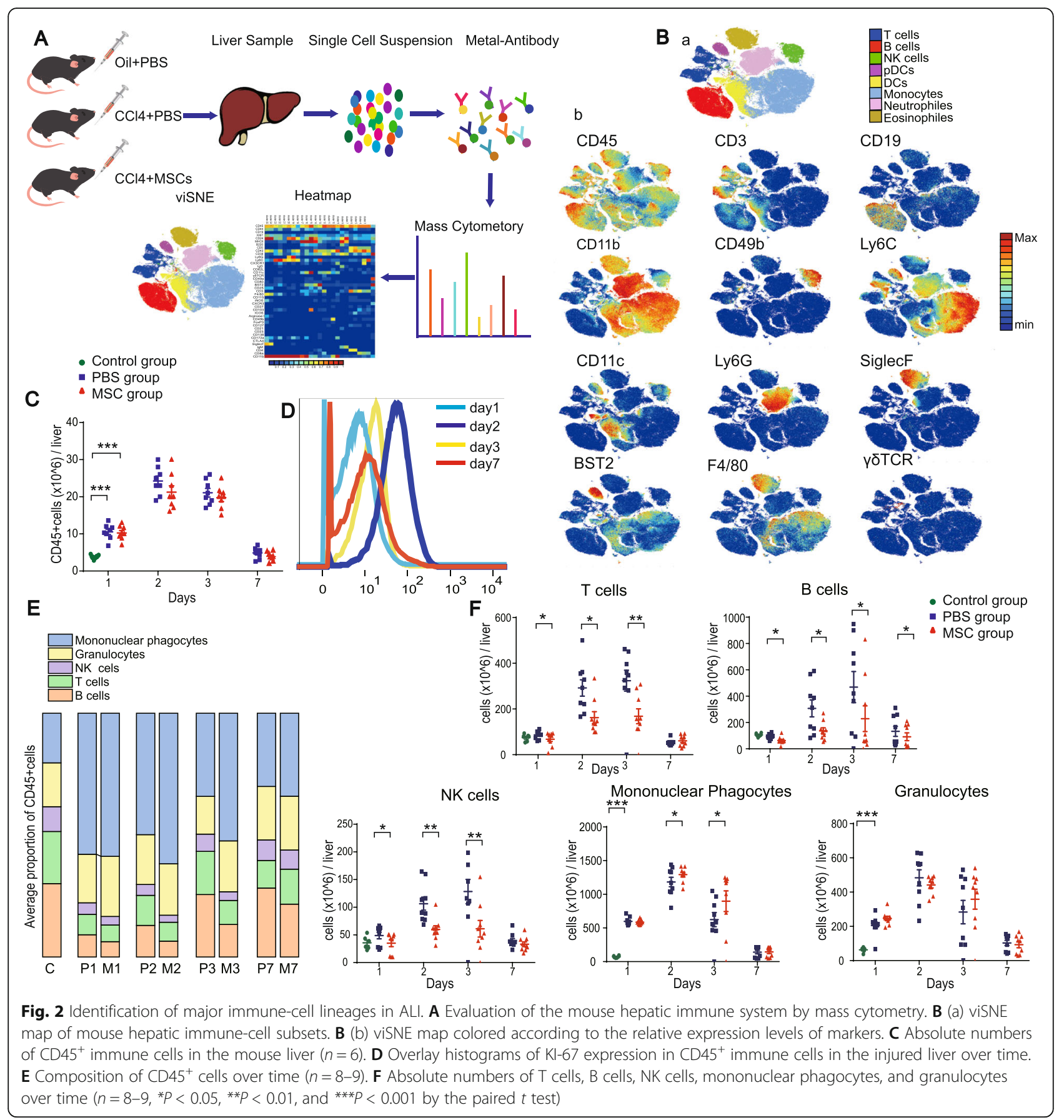

dramatically increased (57.8\%), whereas the proportions of $B$ cells, T cells, and NK cells were markedly lower in the placebo than in the control group (Fig. 2E). Moreover, at 1-3 days after treatment, the numbers of $\mathrm{T}$ cells, $\mathrm{B}$ cells, and NK cells were significantly lower in the MSC-treated liver compared to the placebo-treated liver, whereas the number of mononuclear phagocytes was significantly greater in the MSC-treated liver. These results are consistent with previous reports that MSCs suppress the immune response by inhibiting the proliferation of $\mathrm{B}$ cells, $\mathrm{T}$ cells, and NK cells [6]. The numbers of T cells, NK cells, mononuclear phagocytes, and granulocytes did not differ significantly between the placebo and MSC groups at day 7 $(p>0.05)$, whereas the number of B cells was significantly lower in the MSC group at day 7 (Fig. 2F).

Effects of MSC on the immune system during the injured and recovery phases

We subjected the mass cytometry data to an X-shift algorithm [11, 13], which partitioned the liver immune 
cells into distinct subsets in an unbiased manner (Fig. 2A). Up to 25 clusters were identified (Fig. 3a); the normalized expression of each cluster is shown as a heatmap (Fig. 3b). To globally visualize the distribution and dynamics of liver immune cells, their fingerprint-like characteristics were assessed using viSNE (Fig. 3c). This enabled the identification of clusters that differed between the placebo and MSC groups (Fig. 3c, Table 1, and Additional file 1: Table S2). The placebo and MSCtreated livers displayed distinct cellular signatures during the injured and recovery phases (Fig. 3c). To assess the immune response, we conducted pairwise correlation

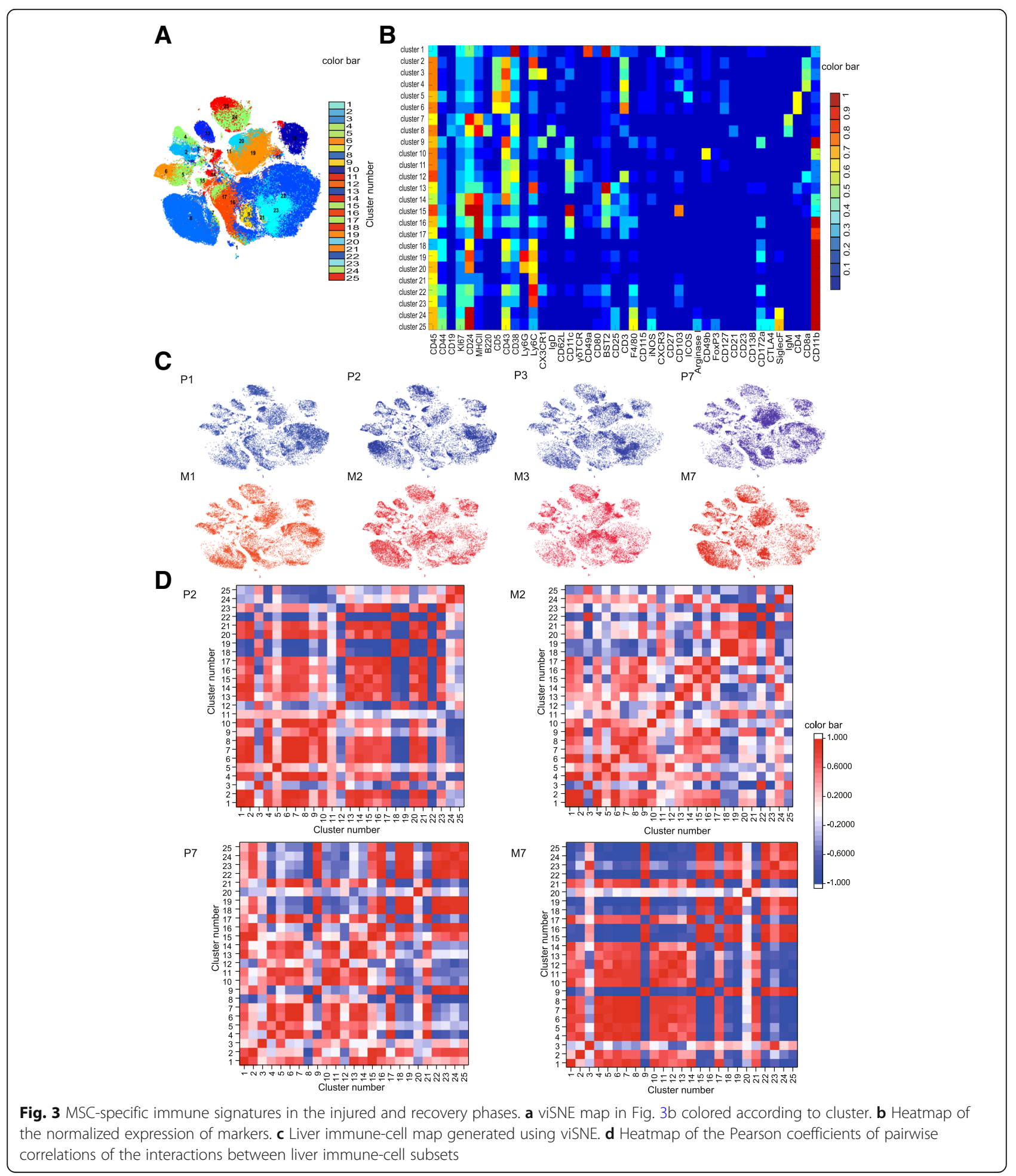


Table 1 Relationships between clusters and hepatic immune-cell populations

\begin{tabular}{|c|c|c|c|c|c|}
\hline \multicolumn{2}{|c|}{ Subsets Label } & \multirow{2}{*}{$\begin{array}{l}\text { Cluster } \\
5\end{array}$} & \multicolumn{2}{|l|}{ Subsets Label } & \multirow{2}{*}{$\begin{array}{l}\text { Cluster } \\
9\end{array}$} \\
\hline$\overline{T \text { cell }}$ & $\mathrm{CD}^{+} \mathrm{T}$ cell & & Mononuclear phagocyte & DC & \\
\hline & & 6 (naïve $C D 4^{+} T$ cell) & & & 13 \\
\hline & $\mathrm{CD}^{+} \mathrm{T}$ cell & $2\left(\right.$ Ly6C $^{\text {hi }}$ CD $\left.^{+} T_{R M}\right)$ & & & 15 \\
\hline & & 3 & & & 16 (moDC) \\
\hline & & $4\left(\right.$ Ly6C $\left.^{\text {low }} \mathrm{CD}^{+} \mathrm{T}_{\mathrm{RM}}\right)$ & & & 17 \\
\hline & үઠ T cell & 12 & & Monocyte/macrophage & 18 \\
\hline \multirow[t]{2}{*}{ B cell } & & $7\left(\operatorname{lgM}^{+}\right.$B cell) & & & 21 \\
\hline & & $8\left(\operatorname{lgM}^{+} \lg D^{+} B\right.$ cell $)$ & & & 22 (Monocyte-derived macrophage) \\
\hline \multirow[t]{2}{*}{ NK cell } & & 1 (liver-resident NK cell) & & & 23 (Monocyte) \\
\hline & & 10 (conventional NK cell) & Granulocyte & Neutrophil & 19 \\
\hline \multirow[t]{3}{*}{ Unknown } & & 11 & & & 20 \\
\hline & & 14 & & Eosinophil & 24 \\
\hline & & & & & 25 \\
\hline
\end{tabular}

analyses of all liver immune-cell subsets (Fig. 3d). The marked differences between the placebo and MSC groups during the injured and recovery phases demonstrate that the MSC-induced immune coordination is dynamic and involves immune cell coordination and response. We thus evaluated the distribution and marker expression of clusters during the injured and recovery phases.

\section{Characteristics of MSC treatment-associated alterations in adaptive immune-cell subsets}

$\mathrm{X}$-shift and $\mathrm{t}$-SNE analyses identified six $\mathrm{T}$ cell subsets, and paired mass cytometry analysis revealed their compositions and phenotypic alterations (Fig. 4 and Additional file 1: Figure S6A-S6C). Marker expression was similar in clusters 2 and 4, in which expression of CD3, CD8, CD5, and CD43 was high and that of CD127 was low. Cluster 4 expressed a high level of integrin CD103 and a low level of Ly6C and thus likely represents $\mathrm{CD}^{+}$tissue-resident memory $\mathrm{T}$ cells ( $\mathrm{Ly}_{6 \mathrm{C}}{ }^{\text {low }} \mathrm{CD}^{+} \mathrm{T}_{\mathrm{RM}}$ ) [14]. Cluster 2 expressed a low level of CD103 and a high level of Ly6C (Figs. 3a, b and 4a). Ly6C is associated with augmented effector function and the activation of $\mathrm{T}$ cells $[15,16]$. We therefore inferred that cluster $2\left(\mathrm{Ly}_{6 \mathrm{C}} \mathrm{CD}^{\mathrm{hi}}\right.$ $\mathrm{T}_{\mathrm{RM}}$ ) represents activated effector $\mathrm{CD}^{+} \mathrm{T}_{\mathrm{RM}}$ cells.

During the injured phase, the number of Ly $6 \mathrm{C}^{\text {low }} \mathrm{CD}^{+}$ $\mathrm{T}_{\mathrm{RM}}$ cells was markedly reduced, with lower expression of CD103 and higher expression of Ly6C in the MSC compared to the placebo group (Fig. 4b, c, and Additional file 1: Figure S6B). Additionally, Ly6C ${ }^{\text {low }} \mathrm{CD}^{+}$ $\mathrm{T}_{\mathrm{RM}}$ cells in the MSC group expressed a low level of CD127 (IL7Ra) (Fig. 4c and Additional file 1: Figure S6B). IL7 contributes to $\mathrm{T}_{\mathrm{RM}}$ survival $[17,18]$. Therefore, although there was no difference in KI67 expression by $\mathrm{Ly}_{6 \mathrm{C}}{ }^{\text {low }} \mathrm{CD}^{+} \mathrm{T}_{\mathrm{RM}}$ cells between the MSC and placebo groups (Fig. 4d, e), the number of $\mathrm{Ly} 6 \mathrm{C}^{\text {low }} \mathrm{CD}^{+}$ $\mathrm{T}_{\mathrm{RM}}$ cells was markedly reduced in the MSC group. Moreover, the number of Ly6 $\mathrm{C}^{\text {hi }} \mathrm{CD}^{+} \mathrm{T}_{\mathrm{RM}}$ cells was decreased and their expression of CD5 and Ly6C was lower in the MSC compared to the placebo group (Fig. 4b, $\mathrm{c}$ and Additional file 1: Figure S6B), suggesting that MSCs suppressed the activation of Ly6C ${ }^{\text {hi }} \mathrm{CD} 8^{+} \mathrm{T}_{\mathrm{RM}}$ cells during the injured phase. $\mathrm{Ly} 6 \mathrm{C}^{\text {hi }} \mathrm{CD} 8^{+} \mathrm{T}_{\mathrm{RM}}$ cells were strongly positively correlated with Ly6C ${ }^{\text {low }} \mathrm{CD}^{+} \mathrm{T}_{\mathrm{RM}}$ cells (Fig. 4f) in the MSC group. Cluster 6 was characterized by the absence of expression of CD38 and ICOS in CD4 ${ }^{+} \mathrm{T}$ cells (Figs. 3a, b and 4a) and thus represents naive $\mathrm{CD}^{+} \mathrm{T}$ cells. The number of naive $\mathrm{CD} 4^{+} \mathrm{T}$ cells was significantly reduced in the MSC group (Fig. 4b).

The number of Ly6C ${ }^{\text {low }} \mathrm{CD}^{+} \mathrm{T}_{\mathrm{RM}}$ cells was markedly increased in the MSC group compared to the placebo group during the recovery phase (Fig. 4b), and their expression of Ly6C and CD103 (associated with the survival of CD8 ${ }^{+} \mathrm{T}_{\mathrm{RM}}$ cells) was significantly lower and higher, respectively (Fig. 4c and Additional file 1: Figure S6C). This suggests that MSCs restored the phenotype of $\mathrm{Ly} 6 \mathrm{C}^{\text {low }} \mathrm{CD}^{+} \mathrm{T}_{\mathrm{RM}}$ cells and promoted their retention. Additionally, Ly6C ${ }^{\text {hi }} \mathrm{CD}^{+} \mathrm{T}_{\mathrm{RM}}$ cells in the MSC group expressed a lower level of Ly6C and naïve $\mathrm{CD}^{+} \mathrm{T}$ cells showed a lower level of CD25 (IL-2Ra subunit) compared to the placebo group during the recovery phase. Therefore, MSCs inhibited the activation and effector function of $\mathrm{Ly}_{6 \mathrm{C}} \mathrm{CD}^{\mathrm{hi}} \mathrm{T}_{\mathrm{RM}}$ cells and decreased the affinity of naïve $\mathrm{CD}^{+} \mathrm{T}$ cells for IL-2R.

We also analyzed the distribution and marker expression of B cells. The mouse liver B cell compartment contained two subsets: $\operatorname{IgM}^{+}$B cells (cluster 7) and $\operatorname{IgM}^{+} \operatorname{IgD}^{+}$ B cells (cluster 8), both of which showed high expression of major histocompatibility complex class II (MHC II), but low expression of the costimulatory receptor CD80 (Figs. 3a, b, and $5 \mathrm{a}$ ). $\operatorname{IgM}^{+} \operatorname{IgD}^{+} \mathrm{B}$ cells were the most 


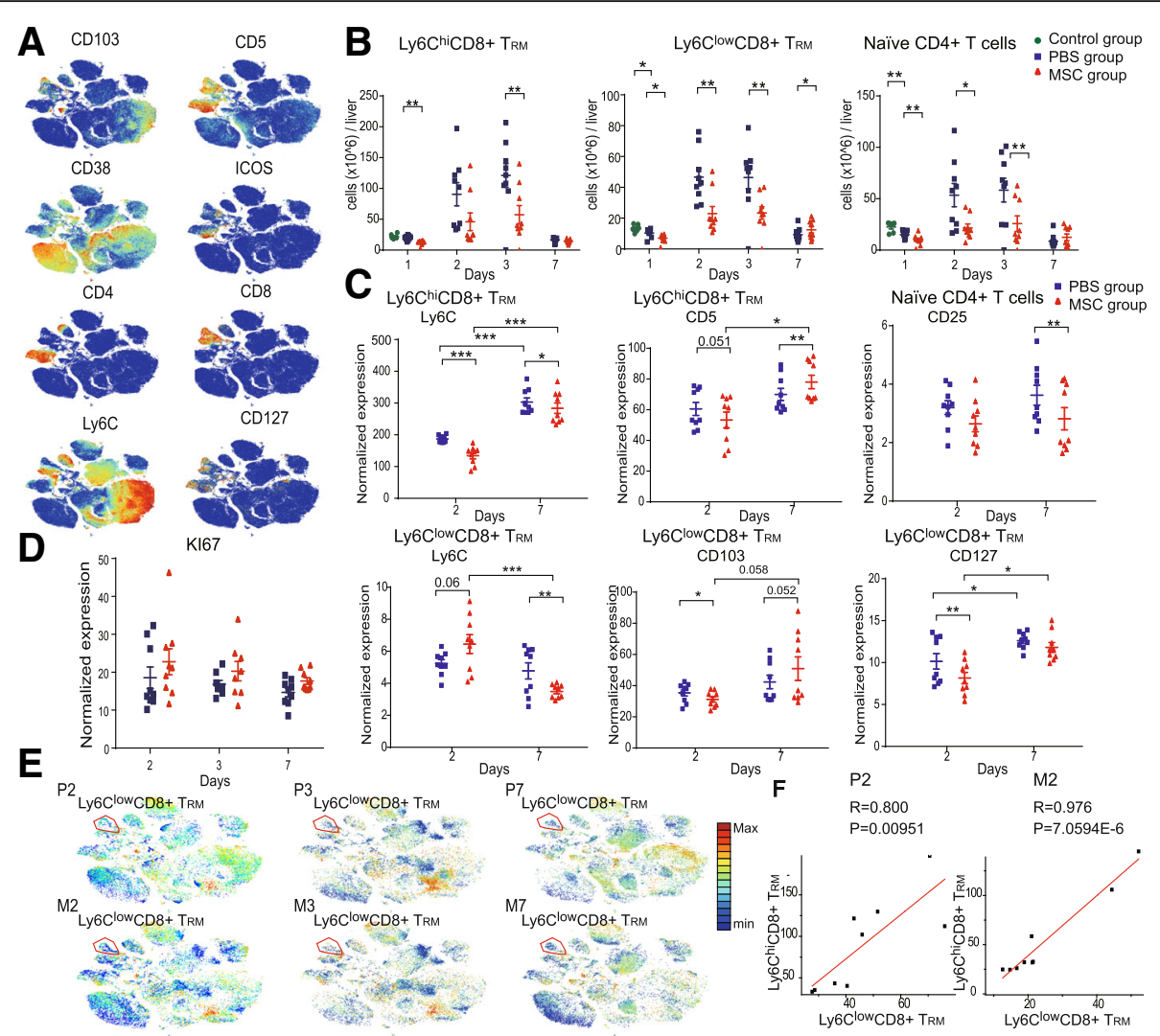

Fig. 4 High-dimensional characteristics of MSC-specific alterations in T cell subsets. a viSNE maps of normalized expression levels of CD103, CD5, CD127, CD38, CD4, CD8, ICOS, and Ly6C. b Absolute numbers of Ly6C ${ }^{\text {low } C D 8} 8^{+} T_{R M}$, Ly6C $C^{\text {hi } C D} 8^{+} T_{R M}$, and naïve CD4 ${ }^{+} T$ cells over time $(n=8-9$, ${ }^{*} P<0.05,{ }^{*} P<0.01$, and ${ }^{* *} P<0.001$ by the paired $t$ test). $\mathbf{c}$ Bar plots of normalized expression of cell-surface markers in the indicated cell subsets $\left(n=8-9,{ }^{*} P<0.05\right.$, ${ }^{*} P<0.01$, and ${ }^{* * *} P<0.001$ by the paired $t$ test). $\mathbf{d}$ Bar plots of normalized KI67 expression. e viSNE map; colors indicate the Kl67 expression levels. $\mathbf{f}$ Correlation plot of Ly6C ${ }^{\text {low } C D 8} 8^{+} T_{R M}$ and Ly6Chi CD8 ${ }^{+} T_{R M}$ cells

abundant subset in the B cell compartment. During the injured and recovery phases, the number of $\operatorname{IgM}^{+} \operatorname{IgD}{ }^{+} \mathrm{B}$ cells was lower with MSC treatment (Fig. 5b). The IgM+ $\mathrm{B}$ cells and $\operatorname{IgM}^{+} \operatorname{IgD}^{+} \mathrm{B}$ cells showed lower expression of MHC II and IgM during the injured phase and higher expression of MHC II during the recovery phase in the MSC compared to the placebo group. $\operatorname{IgM}^{+} \operatorname{IgD}{ }^{+} \mathrm{B}$ cells showed higher expression of IgD in the MSC group during the recovery phase (Fig. 5c, Additional file 1: Figure S6D, S6E). Pelletier et al. reported that the expression of MHC II on $B$ cells is associated with the regulation of $T$ cell responses [19]; therefore, we analyzed the relationships between the $\mathrm{B}$ cell subsets and $\mathrm{T}$ cells. Interestingly, the numbers of $\mathrm{IgM}^{+} \mathrm{IgD}^{+} \mathrm{B}$ cells and $\mathrm{T}$ cells were strongly positively correlated in the placebo group but not the MSC group during the injured phase. In contrast, during the recovery phase, the numbers of $\operatorname{IgM}^{+} \operatorname{IgD}^{+} \mathrm{B}$ cells and $\mathrm{T}$ cells were strongly positively correlated in the MSC group but not in the placebo group (Fig. 5d). Collectively, these data indicate that the correlation between $\operatorname{IgM}^{+} \operatorname{IgD}^{+} \mathrm{B}$ cells and $\mathrm{T}$ cells is associated with higher MHCII expression, consistent with the findings of Pelletier and colleagues.
Taken together, these results demonstrate the complex dynamics of the adaptive immune response induced by ALI, and that MSCs exerted distinct immunomodulatory effects during the injured and recovery phases.

\section{Characteristics of MSC-associated alterations in innate immune-cell subsets}

We also analyzed the innate immune response in the different groups. In the mouse liver, NK cells were present as liver-resident NK cells (cluster 1, $\mathrm{CD} 49 \mathrm{a}^{+} \mathrm{CD} 49 \mathrm{~b}^{-}$) and conventional NK (cNK) cells (clus-

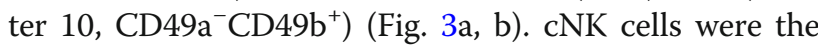
most abundant subset in the NK-cell compartment. During the injured phase, the number of cNK cells was decreased by MSC treatment (Fig. 6a). Moreover, MSC treatment decreased the expression of CD62L in cNKs during the recovery phase (Fig. $6 \mathrm{~b}$ and Additional file 1: Figure S7A). The expression of CD62L on NK cells is correlated with a relatively mature NK cell phenotype and increased cytotoxicity [20]. Thus, MSCs suppressed the proliferation of cNK cells during the injured phase and decreased their cytotoxicity during the recovery 


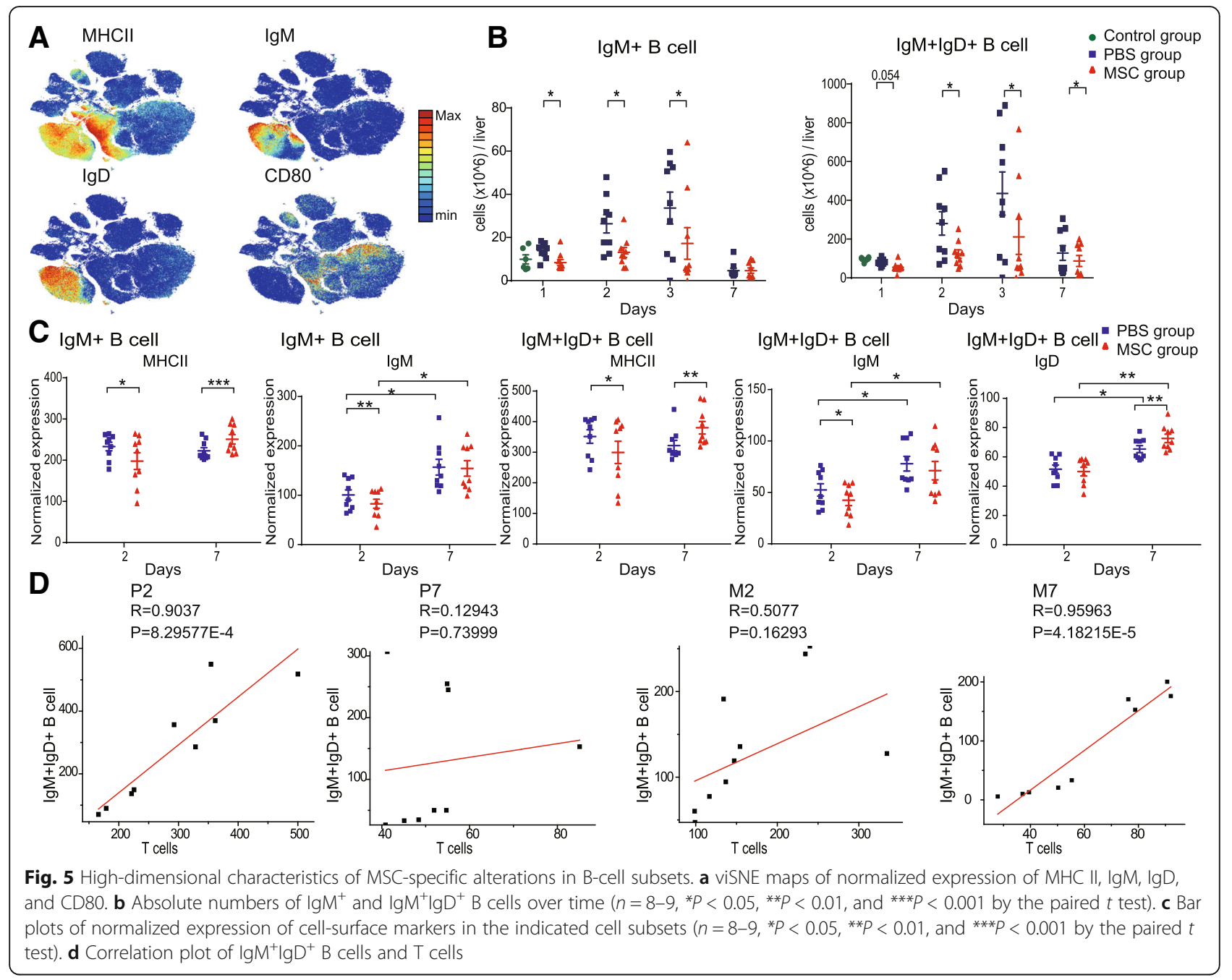

phase. We also found that the number of cNK cells was strongly positively correlated with that of $\mathrm{Ly}_{6} \mathrm{C}^{\text {low }} \mathrm{CD} 8^{+}$ $\mathrm{T}_{\mathrm{RM}}$ cells in the MSC and placebo groups during the injured phase (Fig. 6c and Additional file 1: Figure S7B).

The myeloid cell compartment, which contains granulocytes and mononuclear phagocytes, presents antigens to prime naïve $\mathrm{T}$ cells and induces an adaptive immune response. Myeloid cells dominate the immune microenvironment of the injured liver and are vital for MSCbased treatment of ALI. Therefore, we mapped the distribution and dynamics of myeloid cell subsets.

$\mathrm{X}$-shift and t-SNE analyses identified 13 myeloid-cell subsets, comprising five DC subsets (clusters 9, 13, 15-17), four monocyte subsets (clusters 18, 21-23), and four granulocyte subsets (clusters 19, 20, 24, 25) (Fig. 6d and Additional file 1: Figure S7C). Cluster 16 expressed CD11c, MHCII, Ly6C, and F4/80, consistent with monocytederived DCs (moDCs); CD80, CD44, KI67, BST2, and CX3CR1, indicative of activation; and a middling level of CD38 and the myeloid inhibitory immunoreceptor
CD172a, also termed SIRPa or SHPS-1. Cluster 23 was Ly6C $^{\text {hi }}$ monocytes, and cluster 22 expressed Ly6C, CD44, CX3CR1, F4/80, CD38, and CD172a (Fig. 3a, b and Additional file 1: Figure S5), suggesting that activation and differentiation to a macrophage-like state occurred. The number of moDCs (cluster 16) and monocyte-derived macrophages (cluster 22) decreased, and their expression of CD172a and CD38 increased in the placebo group, during the recovery phase compared to the injured phase (Fig. 6d, e, and Additional file 1: Figure S7D). CD38 is a marker of inflammation-induced differentiation of monocytes to DCs, is expressed by circulating monocytes and M1-polarized murine macrophages, and is a marker of the early innate immune response $[21,22]$. Therefore, moDCs and monocyte-derived macrophages may be derived from circulating monocytes.

During the injured phase, the number of monocyte-derived macrophages was significantly increased by MSC treatment (Fig. 6d). In contrast, during the recovery phase, the number of monocyte-derived macrophages was 


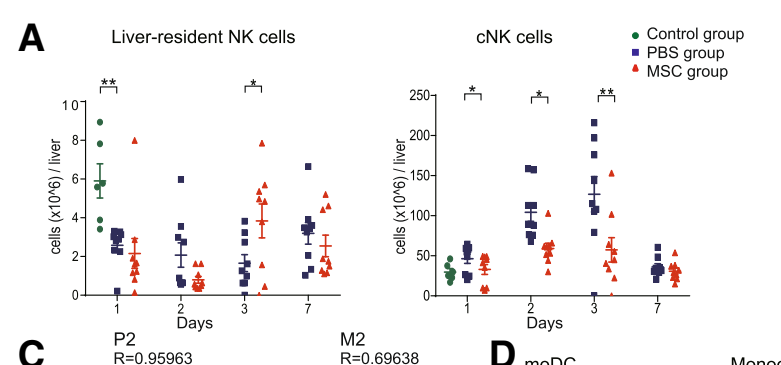

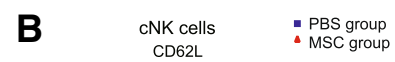
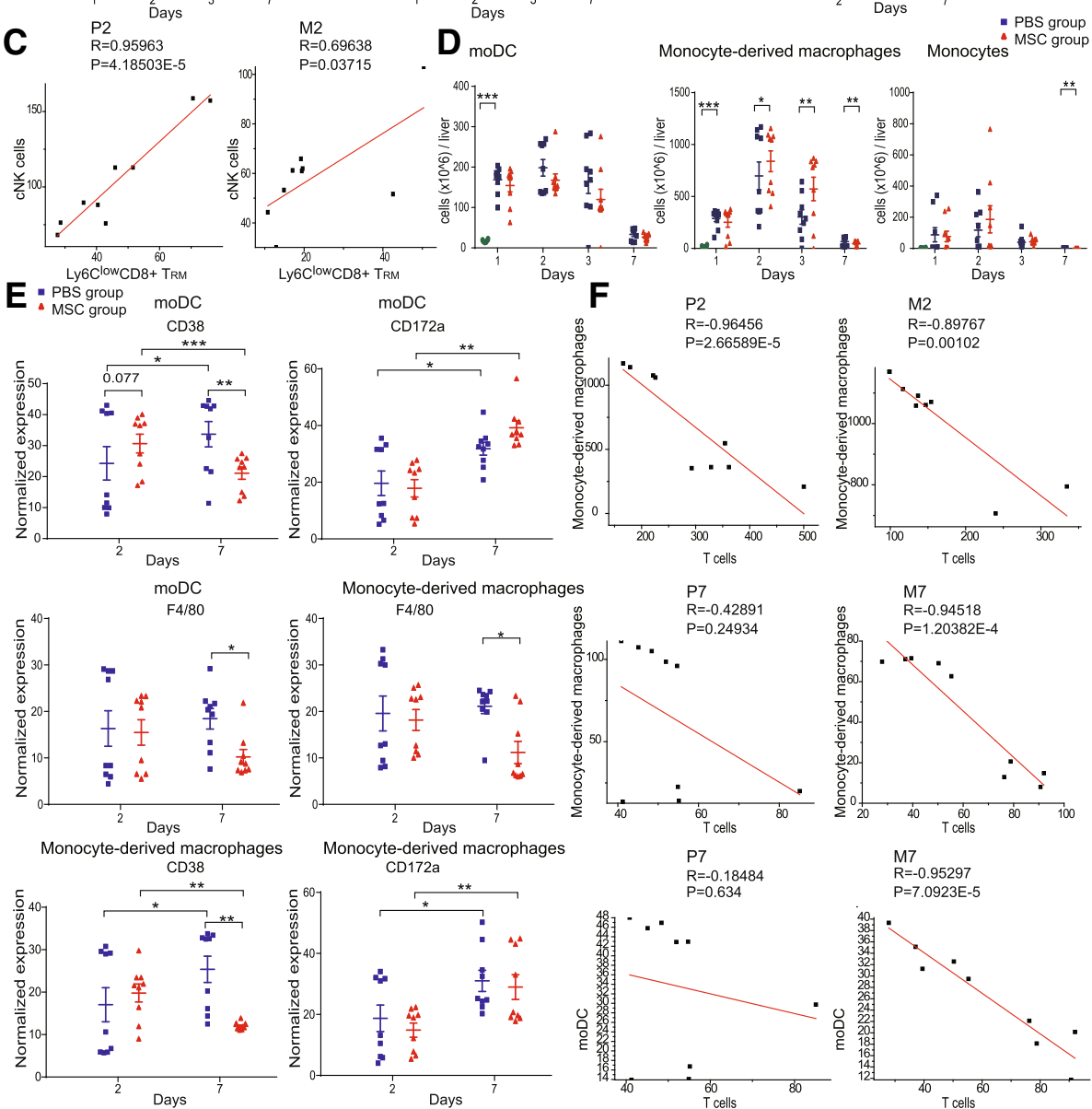

Fig. 6 High-dimensional characteristics of MSC-specific alterations in innate-immune cell subsets. a Absolute numbers of liver-resident NK and CNK cells over time $\left(n=8-9,{ }^{*} P<0.05\right.$, ${ }^{*} P<0.01$, and ${ }^{*}{ }^{*} P<0.001$ by the paired $t$ test). $\mathbf{b}$ Bar plots of normalized expression of CD62L in $\mathrm{CNK}$ cells $\left(n=8-9,{ }^{*} P<0.05,{ }^{*} P<0.01\right.$, and ${ }^{* * *} P<0.001$ by the paired $t$ test). c Correlation plot of cNK cells with Ly6C ${ }^{\text {low } C D 8}{ }^{+} T_{\text {RM }}$. $\mathbf{d}$ Absolute numbers of moDC, monocyte-derived macrophages, and monocytes over time $\left(n=8-9,{ }^{*} P<0.05\right.$, ${ }^{*} P<0.01$, and ${ }^{* * *} P<0.001$ by the paired $t$ test). e Bar plots of normalized expression of F4/80, CD38, and CD172a in moDC and monocyte-derived macrophages $\left(n=8-9\right.$, ${ }^{*} P<0.05$, ${ }^{*} P<0.01$, and ${ }^{* *} P<0.001$ by the paired $t$ test). $\mathbf{f}$ Correlation plot of moDC and monocyte-derived macrophages with $T$ cells

markedly decreased by MSC treatment, and CD38 and F4/ 80 expression in monocyte-derived macrophages and moDCs was lower in the MSC than in the placebo group during the recovery phase (Fig. $6 \mathrm{~d}$, e, and Additional file 1: Figure S7E). Because DCs and monocytes present antigens to prime $\mathrm{T}$ cells, we evaluated their relationships. The numbers of moDCs, monocyte-derived macrophages, and $\mathrm{T}$ cells were strongly correlated. Also, the number of monocyte-derived macrophages was strongly negatively correlated with that of $\mathrm{T}$ cells in the MSC and placebo groups during the injured phase (Fig. 6f). In contrast, during the recovery phase, the numbers of moDCs and monocyte-derived macrophages were strongly negatively correlated with that of T cells in the MSC but not in the placebo group (Fig. $6 \mathrm{f}$ and Additional file 1: Figure S7F).

\section{Changes in CD43 after MSC treatment in the injured and recovery phases}

The mass cytometry results suggested CD43, an abundant transmembrane glycoprotein, to be a marker of the 
immunomodulatory effects of MSCs in ALI. During the injured phase, $C D 43$ expression in $\mathrm{Ly}_{6} \mathrm{C}^{\text {low }} \mathrm{CD} 8^{+} \mathrm{T}_{\mathrm{RM}}$, Ly6C $^{\text {hi }} \mathrm{CD}^{+} \mathrm{T}_{\mathrm{RM}}$, and naïve $\mathrm{CD} 4^{+} \mathrm{T}$ cells and cNK cells was lower in the MSC than in the placebo group (Additional file 1: Figure S8A and S8C). During the recovery phase, CD43 expression in Ly6C ${ }^{\text {low }} \mathrm{CD}^{+} \mathrm{T}_{\mathrm{RM}}$, Ly6C $\mathrm{C}^{\text {hi }} \mathrm{CD} 8^{+}$ $\mathrm{T}_{\mathrm{RM}}$, and naïve $\mathrm{CD} 4^{+} \mathrm{T}$ cells, cNK cells, and monocyte-derived macrophages was higher in the MSC group (Additional file 1: Figure S8B and S8C). However, the function of CD43 is elusive. CD43 has been reported to play both anti- and pro-adhesive roles and to suppress the activation and proliferation of $\mathrm{T}$ lymphocytes, NK cells, and monocytes [23]. However, other studies have found CD43 to promote the activation of lymphocytes [24-26]. The relevance of CD43 to the immunomodulatory effect of MSCs is unclear but is suggested by the similar changes in its expression in T cell subsets, NK cells, and monocyte-derived macrophages following MSC treatment.

\section{Discussion}

The effective treatment of ALI is a concern worldwide, and MSC transplantation can ameliorate liver injury because of its immunomodulatory effects. There is an urgent need to understand the interactions between the complex hepatic immune system and MSCs in ALI. Here, we used mass cytometry to profile the MSC-induced alterations of the hepatic immune system in terms of both the distribution of immune-cell subsets and the phenotypes of single cells.
Our results showed that the MSC-induced immune response differed between the injured and recovery phases of ALI, including in terms of the composition and phenotype of immune cells as well as the relationships between immune-cell subsets (Fig. 7).

During the injured phase, MSC treatment decreased the number of Ly6C ${ }^{\text {low }} \mathrm{CD}^{+} \mathrm{T}_{\mathrm{RM}}$ cells by downregulating the expression of CD127, the $\alpha$-chain of the IL- 7 receptor, which promotes the survival of $\mathrm{T}_{\mathrm{RM}}$ cells [17]. Ly6C is associated with activated $\mathrm{T}$ cells, and Ly6 $\mathrm{C}^{\text {hi }} \mathrm{CD} 8^{+} \mathrm{T}$ cells produce high levels of cytokines and granzymes to control acute infection $[15,16,27]$. MSCs promoted the activation of $\mathrm{Ly} 6 \mathrm{C}^{\text {low }} \mathrm{CD} 8^{+} \mathrm{T}_{\mathrm{RM}}$ cells by downregulating $\mathrm{CD} 103$ expression and upregulating Ly6C expression, but inhibited the activation of its effector counterpart, $\mathrm{Ly} 6 \mathrm{C}^{\mathrm{hi}} \mathrm{CD} 8^{+} \mathrm{T}_{\mathrm{RM}}$, by reducing the expression of CD5 and Ly6C. MSCs also reduced the number of B cells and suppressed their IgM production and antigen presentation by downregulating MHC II expression. The numbers of $\mathrm{B}$ cell subsets were strongly positively correlated with those of $\mathrm{T}$ cells in the placebo but not the MSC group, suggesting that MSCs downregulated MHC II on the surface of B cells to dampen interactions between $\mathrm{T}$ and $\mathrm{B}$ cells, thereby inhibiting the $\mathrm{T}$ cell response. Interestingly, $\mathrm{CD} 8^{+} \mathrm{T}_{\mathrm{RM}}$ cells promote the recruitment of NK cells to injured tissues [28], and the number of cNK cells was strongly positively correlated with that of $\mathrm{Ly} 6 \mathrm{C}^{\text {low }} \mathrm{CD} 8^{+} \mathrm{T}_{\mathrm{RM}}$ cells in the MSC and placebo groups. Thus, the reduced number of $\mathrm{Ly}_{6} \mathrm{C}^{\text {low }} \mathrm{CD}^{+}$

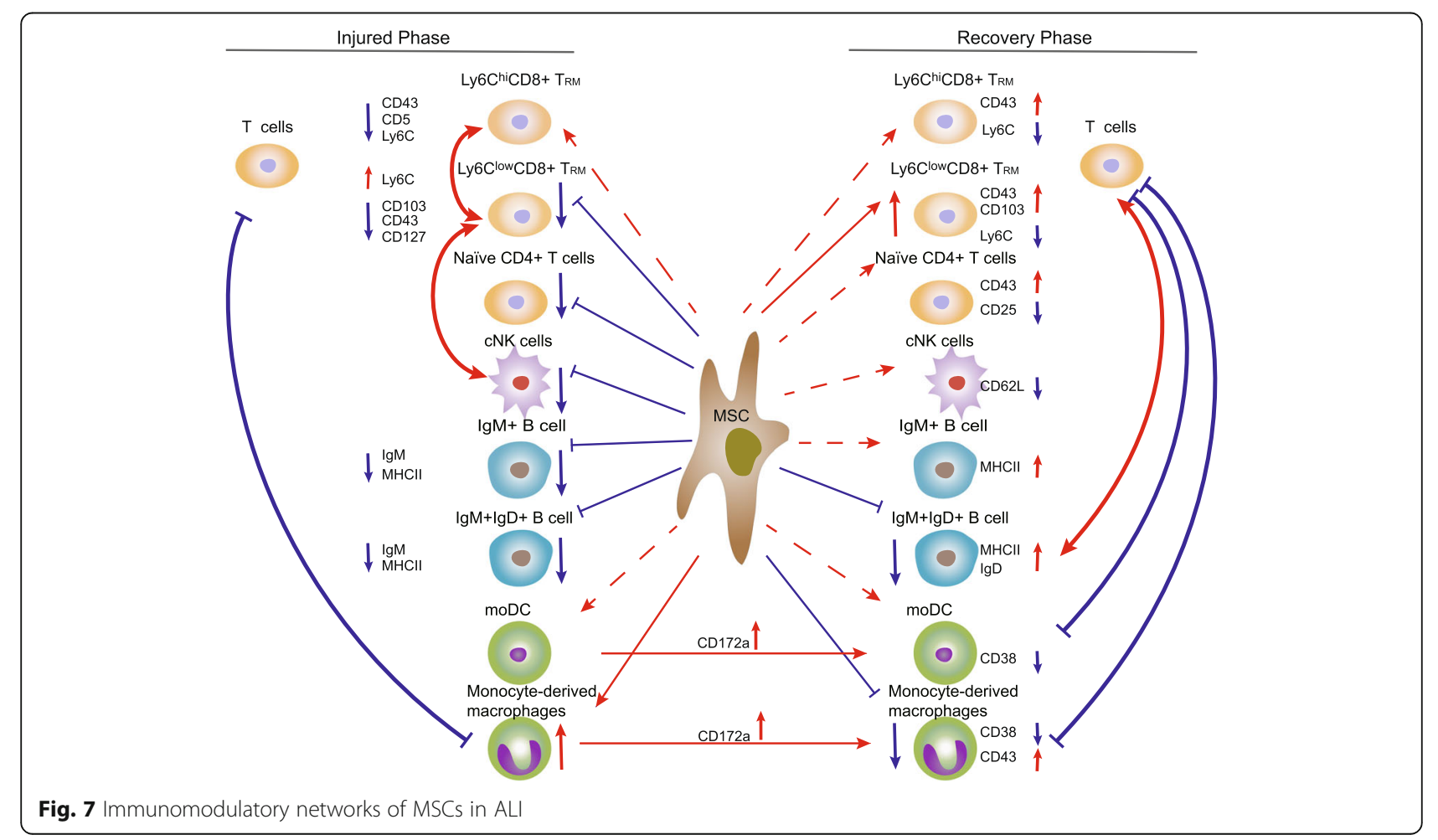


$\mathrm{T}_{\mathrm{RM}}$ cells in the MSC-treated liver might have contributed to the paucity of cNK cells. MSC treatment increased the number of monocyte-derived macrophages, which was strongly negatively correlated with the number of $\mathrm{T}$ cells in the MSC and placebo groups, suggesting that monocyte-derived macrophages play an immunosuppressive role (Fig. 7). Collectively, these results suggest that MSCs inhibit the systemic immune response during the injured phase.

The MSC-induced systemic response was more complex during the recovery phase than the injured phase. The number and $\mathrm{CD} 103$ expression of $\mathrm{Ly}^{6} \mathrm{C}^{\text {low }} \mathrm{CD}^{+}$ $\mathrm{T}_{\mathrm{RM}}$ cells was markedly increased in the MSC group during the recovery phase [29]. This indicates that MSCs restored the phenotype of $\mathrm{Ly} 6 \mathrm{C}^{\text {low }} \mathrm{CD}^{+} \mathrm{T}_{\mathrm{RM}}$ cells, and upregulation of $\mathrm{CD} 103$ promoted the maintenance of Ly6C ${ }^{\text {low }} \mathrm{CD}^{+} \mathrm{T}_{\mathrm{RM}}$ cells. Upon reinfection, hepatic $\mathrm{T}_{\mathrm{RM}}$ cells are the first line of defense, quickly eliminating pathogens and promoting protective immunity in the liver [28]. Thus, the larger number of $\mathrm{Ly} 6 \mathrm{C}^{\mathrm{low}} \mathrm{CD}^{+} \mathrm{T}_{\mathrm{RM}}$ cells in the MSC-treated liver may enhance protection against reinfection. Additionally, MSCs inhibited the effector function and activation of $\mathrm{Ly}_{6} \mathrm{C}^{\mathrm{hi}} \mathrm{CD} 8^{+} \mathrm{T}_{\mathrm{RM}}$ cells and decreased the CD25 (IL-2Ra subunit) expression of naïve $\mathrm{CD} 4^{+} \mathrm{T}$ cells (Fig. 7). Thus, IL-2 primes naïve $\mathrm{T}$ cells and promotes their Th1/Th2 differentiation by modulating the expression of IL-2R [30]. Hence, MSCs suppress the differentiation and priming of naïve $\mathrm{CD} 4^{+} \mathrm{T}$ cells.

MSCs reportedly either suppress B cell proliferation and downregulate costimulatory molecules (CD40, CD80, and CD86), or promote their expansion without affecting the expression of costimulatory molecules, secretion of antibodies, or antigen presentation [31, 32]. Therefore, the effects of MSCs on B cells may depend on the microenvironment. In this study, the number of $\mathrm{IgM}^{+} \operatorname{IgD}{ }^{+} \mathrm{B}$ cells was significantly reduced in the MSCtreated livers, and MSCs enhanced the antigen presentation and IgD secretion of the $\mathrm{B}$ cell subsets during the recovery phase (Fig. 7). The relevance of the composition and phenotype of $\operatorname{IgM}^{+} \operatorname{IgD}^{+} \mathrm{B}$ cells to MSC-based therapy is unclear; further studies are needed.

During the recovery phase, MSCs downregulated CD62L expression in cNK cells. CD62L increases the cytotoxicity of NK cells [20], which may explain why MSCs suppressed the cytotoxic function of cNK cells. MSC treatment decreased the number of monocyte-derived macrophages, and the number of moDCs and monocyte-derived macrophages was strongly negatively correlated with that of T cells in the MSC but not in the placebo group (Fig. 7). CD172a suppresses the activation of myeloid cells [33], and CD38 enhances the engulfment of apoptotic cells and priming of the $\mathrm{T}$ cell response by myeloid cells [21]. We therefore hypothesized that the immunosuppressive role of moDCs and monocyte-derived macrophages in the MSC-treated liver is linked to the upregulation of CD172a and downregulation of $\mathrm{CD} 38$ during the recovery compared to the injured phase.

CD43 is important for the activation and proliferation of $\mathrm{T}$ lymphocytes, NK cells, and monocytes. CD43 reportedly inhibits the activation and proliferation of $\mathrm{T}$ lymphocytes and NK cells $[23,34]$ or promotes the activation and effects of lymphocytes [24-26]. In this study, CD43 expression in the $\mathrm{T}$ cell subsets, cNK cells, and monocyte-derived macrophages was downregulated during the injured phase and upregulated during the recovery phase. These results suggest that CD43 is a marker of the immunomodulatory effect of MSCs in ALI.

\section{Conclusions}

We evaluated the effect of MSCs on the immune system of the injured liver and performed a system-wide assessment of their immunomodulatory effects. The systemic immune response to MSCs differed between the injured and recovery phases, including in terms of the distribution and phenotype of immune cells and the relationships between immune-cell subsets. Our data enhance understanding of the immunomodulatory effect of MSCs, which will facilitate the development of rational immunotherapies for ALI.

\section{Additional file}

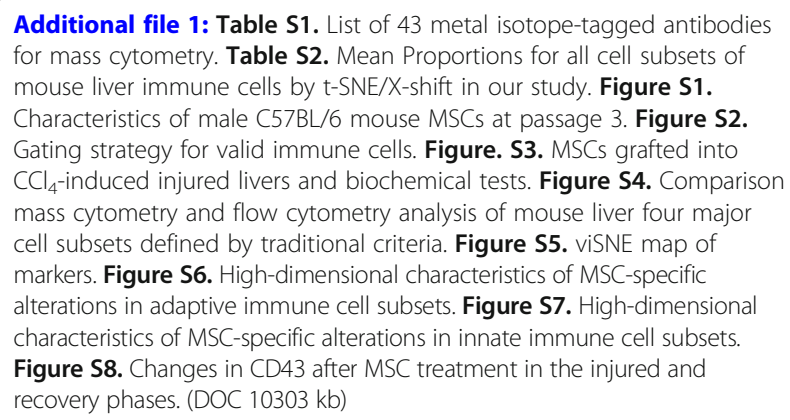

Additional file 1: Table S1. List of 43 metal isotope-tagged antibodies for mass cytometry. Table S2. Mean Proportions for all cell subsets of mouse liver immune cells by t-SNE/X-shift in our study. Figure S1. Characteristics of male C57BL/6 mouse MSCs at passage 3. Figure S2. Gating strategy for valid immune cells. Figure. S3. MSCs grafted into $\mathrm{CCl}_{4}$-induced injured livers and biochemical tests. Figure S4. Comparison mass cytometry and flow cytometry analysis of mouse liver four major cell subsets defined by traditional criteria. Figure S5. viSNE map of markers. Figure S6. High-dimensional characteristics of MSC-specific alterations in adaptive immune cell subsets. Figure S7. High-dimensional characteristics of MSC-specific alterations in innate immune cell subsets. Figure S8. Changes in CD43 after MSC treatment in the injured and recovery phases. (DOC $10303 \mathrm{~kb}$ )

\section{Abbreviations}

ALI: Acute liver injury; ALT: Alanine aminotransferase; AST: Aspartate aminotransferase; $\mathrm{CCl}_{4}$ : Carbon tetrachloride; $\mathrm{CNK}$ cell: Conventional natural killer cell; DC: Dendritic cell; GFP: Green fluorescent protein;

moDC: Monocyte-derived dendritic cell; MSC: Mesenchymal stem cell; NK cell: Natural killer cell

\section{Acknowledgements}

We would like to thank Dr. Hongyu Shi for their support during mass cytometry sample preparation and data acquiring. We also thank Dr. Yanyuan Li of Department of Pathology at the First Affiliated Hospital of Zhejiang University for her review of histopathology.

\section{Authors' contributions}

$J \mathrm{~L}$ and $\mathrm{HC}$ contributed to the study concept and design. $J \mathrm{~L}, \mathrm{BF}, \mathrm{YX}, \mathrm{QP}$, and JZ contributed to ALI models and cell experiments. JL, WC, XS, JY, and XZ contributed to the data analysis and statistical analysis. $J$, LL, and HC contributed to the manuscript writing. All authors have read and approved the final manuscript. 


\section{Funding}

This work was supported by grants for Stem Cell and Translational Research from the National Key Research and Development Program of China (No. 2016YFA0101001) and the National Natural Science Foundation of China (No. 81620108028)

\section{Availability of data and materials}

All data generated or analyzed during this study are included in this article.

\section{Ethics approval}

All animal experimental procedures were conducted according to a protocol approved by the Ethics Committee of the First Affiliated Hospital of Zhejiang University.

\section{Consent for publication}

Not applicable.

\section{Competing interests}

The authors declare that they have no competing interests.

\section{Author details}

'State Key Laboratory for the Diagnosis and Treatment of Infectious Diseases, The First Affiliated Hospital, College of Medicine, Zhejiang University, 79 Qingchun Rd, Hangzhou City 310003, China. ${ }^{2}$ National Clinical Research Center for Infectious Diseases, The First Affiliated Hospital, College of Medicine, Zhejiang University, 79 Qingchun Rd, Hangzhou City 310003, China. ${ }^{3}$ College of Medicine, Zhejiang University, 866 Yuhangtang Rd, Hangzhou City 310058, China. ${ }^{4}$ Zhejiang Provincial Key Laboratory for Diagnosis and Treatment of Aging and Physic-chemical Injury Diseases, 79 Qingchun Rd, Hangzhou City 310003, China.

Received: 23 April 2019 Revised: 6 August 2019

Accepted: 8 August 2019 Published online: 23 August 2019

\section{References}

1. Bernal W, Auzinger G, Dhawan A, Wendon J. Acute liver failure. Lancet. 2010;376(9736):190-201.

2. Kisseleva T, Brenner DA. The phenotypic fate and functional role for bone marrow-derived stem cells in liver fibrosis. J Hepatol. 2012;56(4):965-72.

3. Kuo TK, Hung SP, Chuang CH, Chen CT, Shih YRV, Fang SCY, et al. Stem cell therapy for liver disease: parameters governing the success of using bone marrow mesenchymal stem cells. Gastroenterology. 2008;134(7):2111-21.

4. Uccelli A, Moretta L, Pistoia V. Mesenchymal stem cells in health and disease. Nat Rev Immunol. 2008;8(9):726-36.

5. Singer NG, Caplan Al. Mesenchymal stem cells: mechanisms of inflammation. Annu Rev Pathol. 2011;6:457-78.

6. Volarevic V, Nurkovic J, Arsenijevic N, Stojkovic M. Concise review: therapeutic potential of mesenchymal stem cells for the treatment of acute liver failure and cirrhosis. Stem Cells. 2014;32(11):2818-23.

7. Spitzer MH, Carmi Y, Reticker-Flynn NE, Kwek SS, Madhireddy D, Martins $M M$, et al. Systemic immunity is required for effective cancer immunotherapy. Cell. 2017;168(3):487.

8. Lavin Y, Kobayashi S, Leader A, Amir ED, Elefant N, Bigenwald C, et al. Innate immune landscape in early lung adenocarcinoma by paired single-cell analyses. Cell. 2017;169(4):750-65 e17.

9. Korin B, Ben-Shaanan TL, Schiller M, Dubovik T, Azulay-Debby H, Boshnak NT, et al. High-dimensional, single-cell characterization of the brain's immune compartment. Nat Neurosci. 2017;20(9):1300-9.

10. Chevrier S, Levine JH, Zanotelli VRT, Silina K, Schulz D, Bacac M, et al. An immune atlas of clear cell renal cell carcinoma. Cell. 2017;169(4):736-49 e18.

11. Kimball AK, Oko LM, Bullock BL, Nemenoff RA, van Dyk LF, Clambey ET. A Beginner's guide to analyzing and visualizing mass cytometry data. J Immunol. 2018;200(1):3-22

12. van der Maaten, L. Accelerating t-SNE using Tree-Based Algorithms. J Mach Learn Res. 2014;15:3221-45.

13. Amir el AD, Davis KL, Tadmor MD, Simonds EF, Levine JH, Bendall SC, et al. viSNE enables visualization of high dimensional single-cell data and reveals phenotypic heterogeneity of leukemia. Nat Biotechnol. 2013;31(6):545-52.

14. Mueller SN, Mackay LK. Tissue-resident memory T cells: local specialists in immune defence. Nat Rev Immunol. 2016;16(2):79-89.
15. DeLong JH, Hall AO, Konradt C, Coppock GM, Park J, Harms Pritchard G, et al. Cytokine- and TCR-mediated regulation of T cell expression of Ly6C and Sca-1. J Immunol. 2018;200(5):1761-70.

16. Jaakkola I, Merinen M, Jalkanen S, Hanninen A. Induces clustering of LFA-1 (CD11a/CD18) and is involved in subtype-specific adhesion of CD8 T cells. J Immunol. 2003;170(3):1283-90.

17. Carrette F, Surh CD. IL-7 signaling and CD127 receptor regulation in the control of T cell homeostasis. Semin Immunol. 2012;24(3):209-17.

18. Schenkel JM, Masopust D. Tissue-resident memory T cells. Immunity. 2014 41(6):886-97.

19. Pelletier N, McHeyzer-Williams LJ, Wong KA, Urich E, Fazilleau N, McHeyzerWilliams MG. Plasma cells negatively regulate the follicular helper T cell program. Nat Immunol. 2010;11(12):1110-8.

20. Peng $H$, Sun $R$, Tang L, Wei $H$, Tian Z. CD62L is critical for maturation and accumulation of murine hepatic NK cells in response to viral infection. J Immunol. 2013;190(8):4255-62.

21. Amici SA, Young NA, Narvaez-Miranda J, Jablonski KA, Arcos J, Rosas L, et al. CD38 is robustly induced in human macrophages and monocytes in inflammatory conditions. Front Immunol. 2018;9:1593.

22. Lischke THK, Schumacher V, Schneider M, Haag F, Koch-Nolte F, Mittrücker HW. CD38 controls the innate immune response against Listeria monocytogenes. Infect Immun. 2013;81(11):4091-9.

23. Onami TM, Harrington LE, Williams MA, Galvan M, Larsen CP, Pearson TC, et al. Dynamic regulation of T cell immunity by CD43. J Immunol. 2002; 168(12):6022-31

24. Burke B, Ahmad R, Staples KJ, Snowden R, Kadioglu A, Frankenberger M, et al. Increased TNF expression in CD43(++) murine blood monocytes. Immunol Lett. 2008;118(2):142-7.

25. Nieto M, Rodríguez-Fernández $J$, Navarro F, Sancho D, Frade JM, Mellado M, Martínez-A C, et al. Signaling Through CD43 Induces natural killer cell activation, chemokine release, and PYK-2 activation. Blood. 1999;94(8):2767-77.

26. Pedraza-Alva G, Merida LB, del Rio R, Fierro NA, Cruz-Munoz ME, Olivares N, et al. CD43 regulates the threshold for $T$ cell activation by targeting $\mathrm{Cbl}$ functions. IUBMB Life. 2011;63(10):940-8.

27. Lee JY, Kim J, Yi J, Kim D, Kim HO, Han D, et al. Phenotypic and functional changes of peripheral Ly6C(+) T regulatory cells driven by conventional effector T cells. Front Immunol. 2018;9:437.

28. Walk J, Stok JE, Sauerwein RW. Can patrolling liver-resident T cells control human malaria parasite development? Trends Immunol. 2019;e-pub ahead of print Jan 31. https://doi.org/10.1016/j.it.2019.01.002.

29. Topham DJ, Reilly EC. Tissue-resident memory CD8(+) T cells: from phenotype to function. Front Immunol. 2018;9:515.

30. Voisinne G, Gonzalez de Peredo A, Roncagalli R. CD5, an undercover regulator of TCR signaling. Front Immunol. 2018;9:2900

31. Corcione A, Benvenuto F, Ferretti E, Giunti D, Cappiello V, Cazzanti F, et al Human mesenchymal stem cells modulate B-cell functions. Blood. 2006; 107(1):367-72.

32. Luk F, Carreras-Planella L, Korevaar SS, de Witte SFH, Borras FE, Betjes MGH, et al. Inflammatory conditions dictate the effect of mesenchymal stem or stromal cells on B cell function. Front Immunol. 2017:8:1042.

33. Barclay AN, Van den Berg TK. The interaction between signal regulatory protein alpha (SIRPalpha) and CD47: structure, function, and therapeutic target. Annu Rev Immunol. 2014;32:25-50.

34. Manjunath NCM, Ardman M, Ardman B. Negative regulation of T-cell adhesion and activation by CD43. Nature. 1995;377(6549):535-8.

\section{Publisher's Note}

Springer Nature remains neutral with regard to jurisdictional claims in published maps and institutional affiliations. 